\title{
The ABO Blood Group Distribution and Pulmonary Tuberculosis
}

RAO B.N., REDDY V.D., SAHU P.S., VEERENDRA KUMAR A., DAVID M.A., YUGANDHAR P., MURALISHWAR RAO J.

\section{ABSTRACT}

Aim: Over the years, large number of studies have examined the possible relationship between the blood group type and infection. The present study was aimed at observing the pattern of the $\mathrm{ABO}$ blood group distribution among the pulmonary tuberculosis patients from the Andhra region of the Andhra Pradesh state, India.

Methods: The ABO blood grouping and Rhesus typing were performed by using the standard slide agglutination reaction in 100 patients with a clinical and a radiological evidence of pulmonary tuberculosis and in 1400 healthy controls.

Results: A significant association was observed between the incidence of tuberculosis and the blood groups $B$ and $A B$
( $P$ values are 0.048 and 0.03 respectively). The association between the incidence of tuberculosis and the blood groups $A$ and $O$ ( $P$ values are 0.249 and 0.069 respectively) was found insignificant. However, a significant association between the incidence of tuberculosis and a positive Rhesus antigen was observed in the blood group $A$ ( $P$ value is 0.009). But there was no significant association between the incidence of tuberculosis and a positive Rhesus antigen with the blood groups $B$, $\mathrm{AB}$ and $\mathrm{O}$.

Conclusion: The present study showed that there was an association between tuberculosis and the blood groups $B$ and $A B$ in this region of the Andhra Pradesh state.

\section{INTRODUCTION}

Numerous studies which have been done in the past have shown that there was an association between pulmonary tuberculosis and the ABO blood group systems [1-5]. It was also reported earlier that there was a change in the pattern of the immunological response to Mycobacterium tuberculosis in individuals with different blood groups [6]. A study from Ukraine has shown that there was a considerable depression of the proliferative activity of the T-lymphocytes of sick persons with the blood groups $\mathrm{O}$ and $\mathrm{B}$ and of the specific immunity of patients with the blood group $\mathrm{O}$ as compared to those of blood group A [6]. Others have shown that the incidence of pulmonary tuberculosis was high in the $\mathrm{O}$ and $\mathrm{B}$ group individuals as compared to that in the A group individuals $[6,7]$. Earlier studies from different regions of India have reported conflicting results on this possible association between the $\mathrm{ABO}$ blood group systems and pulmonary tuberculosis [1,8-13]. Since there existed a considerable variation in the distribution of the blood groups in different regions of India, we made an attempt to find out the pattern of the association of the blood group type and the incidence of tuberculosis within the state of Andhra Pradesh. However, in our earlier studies, we had reported that there was no significant association between the $\mathrm{ABO}$ and the Rh blood groups and pulmonary tuberculosis in the Telengana and the Rayalaseema regions of Andhra Pradesh, India [14,15].

Therefore, the present study was undertaken to find out the possible association between the different blood groups in the $\mathrm{ABO}$ and the Rh systems of classification among the pulmonary tuberculosis patients in the Andhra region of Andhra Pradesh, India.

\section{MATERIALS AND METHODS}

\section{Patients}

The distribution of the ABO blood group and the Rhesus antigen/ factor was investigated in the patients who attended the TB and Chest Department at the Alluri Sita Ramaraju Academy of Medical Sciences (ASRAM), Eluru, Andhra Pradesh, India. A total of 100 patients with a clinical and a radiological evidence of pulmonary tuberculosis were included in the present study.

\section{Healthy Controls}

A total number of 1400 control subjects were also investigated for the distribution of the $\mathrm{ABO}$ blood group and the Rhesus antigen. The control group included healthy students and the staff who were working in the college, who had no individual or family history of tuberculosis.

An informed consent was obtained from all the patients as well as the control subjects. The study was approved by the Institutional Ethical Committee, ASRAM, Eluru.

\section{Clinical Examination and Radiological Investigation}

X-rays of the chest were taken for each of the patients who had a clinical presentation and a history of tuberculosis.

\section{Microbiological Investigation}

Sputum samples were collected from each patient and they were investigated in the Department of Microbiology, ASRAM Hospital for the presence of acid fast bacilli. The standard method of acid fast staining was followed for microscopy and the reporting was carried out as per the recommended protocols [16]. 
The sputum specimens were subjected to culture in case the sputum was negative for acid fast bacilli by direct smear microscopy. The samples were inoculated onto the LJ medium (Hi-Media, India) and the media plates were incubated at $37^{\circ} \mathrm{C}$. The growth was checked up to 14 days. The reporting was done with a reference to the standard strain (ATTC H37Rv).

\section{ABO Blood Grouping and RH Typing}

The ABO blood grouping and the Rhesus typing were performed in the Department of Physiology, ASRAM Hospital, by the standard slide agglutination reaction by using a commercial kit [SPAN Diagnostics Ltd, India] for all the study subjects as well as the control individuals.

\section{Statistical Analysis}

The statistical significance was calculated by using the Epilnfo2000 software package developed by Centre for Disease Control and Prevention (CDC), Atlanta, Georgia State, USA.

\section{RESULTS}

The distribution of the different blood groups and the Rhesus antigen type in tuberculosis patients and in healthy controls are summarized in [Table/Fig-1]. The results showed a significant association between the incidence of tuberculosis and the blood groups $B$ and $A B$ ( $P$ values are 0.048 and 0.03 respectively). Further, the significant association between the incidence of tuberculosis and a positive Rhesus antigen was also observed ( $\mathrm{P}=0.009)$. Of the total 1400 healthy controls and the 100 tuberculosis patients, the Rhesus antigen test was found to be positive in 1230 healthy (87.85\%) and 97 (97\%) tuberculous subjects respectively.

The data were analyzed to check for a probable association between the Rhesus antigen positivity and the incidence of tuberculosis under the individual blood group types. The results of the Rhesus antigen test under the individual blood group types are summarized in [Table/Fig-2]. A significant association between the incidence of tuberculosis and a positive Rhesus antigen was observed in blood group A individuals ( $P$ value is 0.009). The results of the Rhesus antigen test among the patients and the controls were proportionate when they were compared with blood groups $B$ and $A B$.

\section{DISCUSSION}

A growing body of the literature attempted to correlate the blood groups and their susceptibility to the diseases. However, many of these reports were poorly documented and they had limited scientific validity [17]. Anthropological surveys suggest that the geographic and the racial distribution of the human blood groups reflect the susceptibility of the populations with specific blood types to plague, cholera, smallpox, malaria, diphtheria, Norwalk virus infection and other infectious diseases [17-20]. In one study, it was shown that persons with the blood group A acquired Sarcoidosis more frequently than persons with the blood group 0 [21]. Other studies from India as well as overseas have reported the incidence of tuberculosis with the specific ABO blood group(s) [1-4]. The transmission of the tuberculosis infection occurs from close contacts within a family or household to sparser and casual contacts, even in public places like a bar, garden, etc. [22]

In the present study, we found that there was a significant association between the incidence of tuberculosis and the blood groups $B$ and $A B$. The association between the incidence of tuberculosis and the blood groups $A$ and $O$ was found to be insignificant. These results were contradictory to those of our earlier studies in which we had reported that there was no significant association between the incidence of tuberculosis and the blood groups $B$ or $A B$ in the Telengana and the Rayalaseema regions of Andhra Pradesh, though these were geographically close to the Andhra region (West Godavari District), the present study location [14,15]. Further, this study also showed that there was a higher incidence of tuberculosis

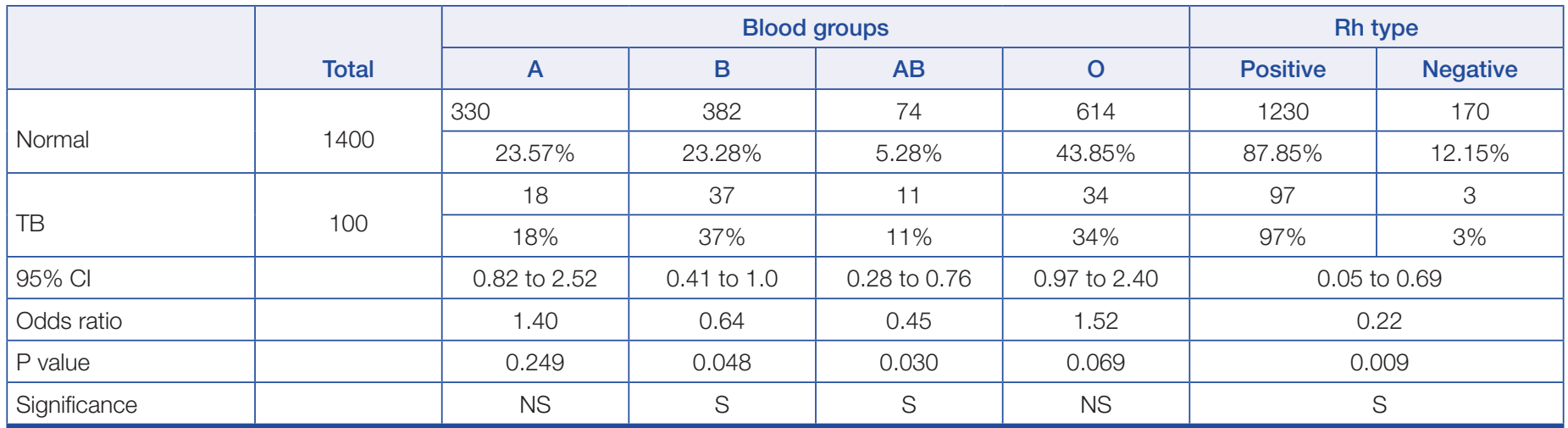

[Table/Fig-1]: Distribution of various ABO blood groups and Rhesus antigen type in patients with tuberculosis and healthy control subjects [Cl: Confidence interval; S: Significant; NS: Not significant; P value: measure of significance by Fisher exact result (2-tailed)]

\begin{tabular}{|c|c|c|c|c|c|c|c|c|}
\hline & \multicolumn{2}{|c|}{ A } & \multicolumn{2}{|c|}{ B } & \multicolumn{2}{|c|}{$A B$} & \multicolumn{2}{|c|}{0} \\
\hline & $\mathrm{Rh}+$ & $\mathrm{Rh}$ - & $\mathrm{Rh}+$ & $\mathrm{Rh}$ - & $\mathrm{Rh}+$ & $\mathrm{Rh}$ - & $\mathrm{Rh}+$ & $\mathrm{Rh}$ - \\
\hline TB & 18 & 0 & 35 & 2 & 9 & 2 & 33 & 1 \\
\hline Normal & 249 & 81 & 369 & 13 & 69 & 5 & 543 & 71 \\
\hline $95 \% \mathrm{Cl}$ & \multicolumn{2}{|c|}{$0.0-0.72$} & \multicolumn{2}{|c|}{0.17 to 7.61} & \multicolumn{2}{|c|}{0.25 to 22.16} & \multicolumn{2}{|c|}{0.01 to 1.43} \\
\hline Odds ratio & \multicolumn{2}{|c|}{0.0} & \multicolumn{2}{|c|}{1.62} & \multicolumn{2}{|c|}{3.07} & \multicolumn{2}{|c|}{0.23} \\
\hline$P$ value & \multicolumn{2}{|c|}{0.009} & \multicolumn{2}{|c|}{0.632} & \multicolumn{2}{|c|}{0.222} & \multicolumn{2}{|c|}{0.160} \\
\hline Significance & \multicolumn{2}{|c|}{ S } & \multicolumn{2}{|c|}{ NS } & \multicolumn{2}{|c|}{ NS } & \multicolumn{2}{|c|}{ NS } \\
\hline
\end{tabular}


in group A individuals with a positive rhesus antigen. However, as to why and how this particular blood group individuals were susceptible to tuberculosis and what is the mechanism behind this variation among the population within a single state, is not known.

A natural resistance to the many infectious diseases is inherent and this natural resistance, to a certain extent, depends on the blood group of an individual. It is known that human erythrocytes possess the surface antigens $\mathrm{A}, \mathrm{B}$ and $\mathrm{AB}$ that determine the blood group of an individual. Type $O$ individuals who do not have neither $A$ nor $B$ develop both anti-A and anti-B antibodies in their serum. Type $A$ individuals who have $A$ antigen, develop anti-B antibodies in their serum. Type $B$ individuals who have $B$ antigen, develop anti- $A$ antibodies in their serum. Type $A B$ individuals who have both $A$ and $B$ antigens, develop neither anti-A and anti-B antibodies in their serum. This determines the natural resistance of an individual to many infectious diseases where the pathogens have antigens on the surfaces of their cells that are similar to the antigens of one or the other blood groups. Thus, the antigens which are similar to those of the blood group A erythrocytes are localized on the pathogens, which are neutralized by the natural antibodies of the blood groups $O$ and $B$. Type $A B$ individuals are more sensitive to the infectious diseases since their serum does not contain the corresponding natural antibodies [23].

However, biochemical studies have revealed that the interaction of the pathogen and erythrocyte membrane may reflect antigenic similarity, adhesion through specific receptors, or modulation of the antibody response $[18,24]$.

Moreover, some studies had shown that there was a correlation between the incidence of a blood group and the ethnic appurtenance and the nationality of the subjects, as was cited in the literature; for instance, in Asian subjects (Kazakhs), the B (III) blood group was much more common, while the $\mathrm{O}(\mathrm{I})$ and the $\mathrm{A}(\mathrm{III})$ blood groups were common in the Europeans. The nature of the specific process depended, to a certain degree, on the blood group [25]. Hence, it was presumed that a study of the $A B O$ and the rhesus pattern among the tuberculosis patients might be biased if a break-down by the bacteriological findings and the history was not made. It is also important that the study covers all the patients who contract tuberculosis within a certain period, as the longevity of the patients is apparent to some extent, to be dependent on their blood groups [26].

However, some studies have shown that the Rh negative patients succumbed to tuberculosis more than the Rh positive patients [26]. The human laeukocyte antigen (HLA) system plays an important role in the modulation of the immune response. An association between HLA and pulmonary tuberculosis has been examined in several populations, but the results have been inconsistent [27]. In one study, among patients with tuberculomas who developed postoperative complications, the carriers of the blood group A (II) were found significantly less frequently. The antigens of HLA were unrelated to the incidence of pulmonary and infectious postoperative complications. However, tuberculosis reactivation in the postoperative period and postoperative recurrences occurred more often in the carriers of the HLA antigen, DR2 [28]. A marginal decrease in DR2 and a concurrent decrease in DRw6 were reported with the HLA-DR typing of tuberculosis patients in a study from north India, though these deviations were statistically insignificant. However, the ABO blood group results indicated the blood group O may afford protection against tuberculosis [4].
In any case, our present study showed that there was an association between tuberculosis and the blood groups $B$ and $A B$ in the Andhra region of the Andhra Pradesh state. However, as we do not have any definite reasons as to why and how this association exists, further studies are clearly warranted to understand the biological relevance of this study.

\section{REFERENCES}

[1] Saha N, Banerjee B. The incidence of the $A B O$ and the $\mathrm{RH}$ blood groups in pulmonary tuberculosis in different ethnic groups. J Med Genet. 1968; 5(4):306-07.

[2] Persson I, Viskum K, Gilberg A, Gessain R. The ABO blood groups and tuberculosis in north and east Greenlanders. Scand J Respir Dis. 1974; 55(2):162-65.

[3] Sozykin VL, Tarasov Al, Efashkina TA. The incidence and the course of tuberculosis of the respiratory organs in persons with different blood groups. Probl Tuberk. 1980; (3):30-33.

[4] Singh SP, Mehra NK, Dingley HB, Pande JN, Vaidya MC. The HLA-A, $-B,-C$ and the -DR antigen profiles in pulmonary tuberculosis in north India. Tissue Antigens. 1983; 21(5):380-84.

[5] Garratty G. The blood groups and disease: a historical perspective. Transfus Med Rev. 2000; 14(4):291-301.

[6] Sybirna RI, Platonova IL, Sakhelashvili MI. The immunological changes which are caused by Mycobacterium tuberculosis in patients with different blood groups. Mikrobiol Z. 1999; 61(4):54-58.

[7] Platonova IL. Metabolic changes in the blood in pulmonary tuberculosis patients with various blood groups. Ukr Biokhim Zh. 1999; 71(5):94-96

[8] Jain RC. The ABO blood groups and pulmonary tuberculosis. Tubercle. 1970; 51(3):322-23.

[9] Shenoy MA, Daftary VG. The ABO blood groups and pulmonary tuberculosis. Indian J Med Sci. 1962; 16:493-98.

[10] Laha PN, Dutta M. Association between the blood groups and pulmonary tuberculosis. J Assoc Physicians India. 1963; 11:287-91.

[11] Kothare SN, Gokhale DS, Gokhale H. The ABO blood groups in relation to pulmonary tuberculosis. J Postgrad Med. 1964; 10: 165-68.

[12] Tyagi SP, Hameed S, Bahadur P, Prasad M, Khare KB. Secretion of blood group specific substances in pulmonary tuberculosis. Indian J Med Res. 1970; 58(5):596-98.

[13] Papiha SS, Singh BN, Lanchbury JS, Roberts DF, Parsad CE, Wentze $J$, et al. Association of HLA and other genetic markers in south Indian patients with pulmonary tuberculosis. Tubercle. 1987; 68(3):159-67.

[14] Reddy VD, Reddy M. Pulmonary tuberculosis and the $A B O$ and the Rh blood groups in the Chittoor district of Rayalaseema in Andhra Pradesh. J NTR UHS. 1998; 3:19-22.

[15] Reddy VD, Usha T. The ABO blood groups and pulmonary tuberculosis in the Warangal district of the Telangana region. J Indian Med Assoc. 1990; 88(12):337-38

[16] Colee JG, Marmion BP, Fraser AG, and Simmons A. In Mackie and McCartny Practical Medical Microbiology. 14th Edition, Churchill Livingstone, New York, 1996.

[17] Rios M, Bianco C. The role of the blood group antigens in infectious diseases. Semin Haematol. 2000; 37(2):177-85.

[18] Berger SA, Young NA, Edberg SC. The relationship between infectious diseases and the human blood types. Eur J Clin Microbiol Infect Dis. 1989;8(8):681-89.

[19] Lindesmith L, Moe C, Marionneau S, Ruvoen N, Jiang X, Lindblad L, et al. Human susceptibility and resistance to the Norwalk virus infection. Nat Med. 2003; 9(5):548-53. Epub 2003 Apr 14.

[20] Guseva EV, Tashpulatov RIU. The blood antigens in the ABO system and the susceptibility of humans to diphtheria. Zh Mikrobiol Epidemiol Immunobiol. 2004;(4):79-81.

[21] Jorgensen G, Wurm K. The ABO blood groups in sarcoidosis. Nature. 1964; 203:1095.

[22] Mori T. The microepidemics of tuberculosis as was revealed by the DNA-fingerprinting of M. tuberculosis. Intern Med. 2004; 43(3): 177-78.

[23] Skripal IG. The ABO system of the blood groups in people and their resistance to certain infectious diseases (prognosis). Mikrobiol $Z$. 1996; 58(2):102-08.

[24] Sandler SG, Mallory D. Biological functions of the blood groups in health and disease. Haematologia (Budap). 1995; 27(1):1-13

[25] Volkova KI, Blinetskaia ZS, Fateev IN. Genetic blood markers of the 
ABO system in patients with pulmonary tuberculosis in relation to their ethnic origin. Probl Tuberk. 1991; (10):55-58.

[26] Viskum K. The $A B O$ and the rhesus blood groups in patients with pulmonary tuberculosis. Tubercle. 1975; 56(4):329-34.

[27] Dubaniewicz A, Szczerkowska Z, Hoppe A. Comparative analysis of the HLA class I antigens in pulmonary sarcoidosis and tuberculosis in the same ethnic group. Mayo Clin Proc. 2003; 78(4):436-42.

[28] Naumov VN, Shaikhaev Ala, Pospelov LE, Testov W. Immunogenetic factors in pulmonary tuberculosis surgery. Probl Tuberk. 1993; (4):17-9.

\section{AUTHOR(S):}

1. DR. Rao B.N.

2. Dr. Reddy V.D.

3. Dr. Sahu P.S.

4. Dr. Veerendra Kumar A.

5. Dr. David M.A.

6. Dr. Yugandhar P.

7. Dr. Muralishwar Rao J.

\section{PARTICULARS OF CONTRIBUTORS:}

1. Associate Professor,Department of Physiology, Shri Sathya Sai Medical College and Research Institute, Ammapettai, Nellikuppam, Tamil Nadu-603108, India.

2. Prof \& HOD, Department of Physiology, Deccan Medical College, Hyderabad, Andhra Pradesh, India.

3. Assistant Professor,Department of Microbiology and Infection Biology Laboratory, School of Biotechnology, KIIT University, Bhubaneswar, Orissa-751024, India.

4. Assistant Professor, Department of Biochemistry, Shri Sathya Sai Medical College and Research Institute, Ammapettai, Nellikuppam, Tamil Nadu-603108, India.

5. Professor, Department of Physiology, Deccan Medical College, Hyderabad, Andhra Pradesh, India.
6. Assistant Professor, Department of TB and Chest Diseases, Alluri Sitarama Raju Academy of Medical Sciences, Eluru, Andhra Pradesh-534 004, India.

7. Assistant Professor, Department of Radio Diagnosis, Alluri Sitarama Raju Academy of Medical Sciences, Eluru, Andhra Pradesh-534 004, India.

\section{NAME, ADDRESS, E-MAIL ID OF THE CORRESPONDING} AUTHOR:

Dr. B. Narasimha Rao,

Associate Professor, Department of Physiology,

Shri Sathya Sai Medical College and Research Institute, Ammapettai, Nellikuppam, Tamil Nadu-603108, India.

Phone: 9176050362

E-mail: raonbodepudi@yahoo.com

\section{FINANCIAL OR OTHER COMPETING INTERESTS:}

None.

Date of Submission: Mar 21, 2012

Date of Peer Review: May 01, 2012

Date of Acceptance: May 04, 2012

Date of Publication: Aug 10, 2012 